\title{
Sensitivity of marine systems to climate and fishing: Concepts, issues and management responses
}

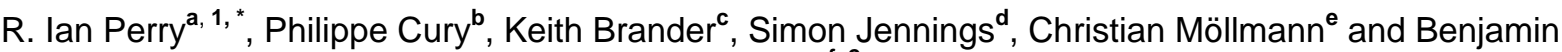 \\ Planque $\mathrm{f}^{\mathrm{f}, 2}$
}

\footnotetext{
${ }^{a}$ Fisheries and Oceans Canada, Pacific Biological Station, Nanaimo, B.C., Canada V9T 6N7

${ }^{b}$ IRD, UMR EME 212, Centre de Recherche Halieutique Méditerranéenne et Tropicale, Avenue Jean Monnet, BP 171, 34203 Sète France

${ }^{c}$ ICES/GLOBEC Coordinator, DTU Aqua - Danish Institute of Aquatic Resources, Technical University of Denmark, Charlottenlund Slot, DK-2920 Charlottenlund, Denmark

${ }^{\mathrm{d}}$ Centre for Environment, Fisheries and Aquaculture Science, Lowestoft Laboratory, Suffolk NR33 OHT, and

School of Environmental Sciences, University of East Anglia, Norwich, NR4 7TJ, United Kingdom

${ }^{\mathrm{e}}$ Institute for Hydrobiology and Fisheries Science, University of Hamburg, Olbersweg 24, D-22767 Hamburg, Germany

${ }^{\mathrm{f}}$ Institut Français de Recherche pour l'Exploitation de la Mer, Département Ecologie et Modèles pour l'Halieutique, rue de l'île d'Yeu, BP21105, 44311 Nantes Cedex 3, France

${ }^{1}$ Equal authorship.

${ }^{2}$ Current address: Institute of Marine Research, Postboks 6404, 9294 Tromso, Norway.
}

\author{
*: Corresponding author : R. Ian Perry, Tel.: +1 250756 7137; fax: +1 250756 7053, email address : \\ lan.Perry@dfo-mpo.gc.ca
}

\begin{abstract}
:
Modern fisheries research and management must understand and take account of the interactions between climate and fishing, rather than try to disentangle their effects and address each separately. These interactions are significant drivers of change in exploited marine systems and have ramifications for ecosystems and those who depend on the services they provide. We discuss how fishing and climate forcing interact on individual fish, marine populations, marine communities, and ecosystems to bring these levels into states that are more sensitive to (i.e. more strongly related with) climate forcing. Fishing is unlikely to alter the sensitivities of individual finfish and invertebrates to climate forcing. It will remove individuals with specific characteristics from the gene pool, thereby affecting structure and function at higher levels of organisation. Fishing leads to a loss of older age classes, spatial contraction, loss of sub-units, and alteration of life history traits in populations, making them more sensitive to climate variability at interannual to interdecadal scales. Fishing reduces the mean size of individuals and mean trophic level of communities, decreasing their turnover time leading them to track environmental variability more closely. Marine ecosystems under intense exploitation evolve towards stronger bottom-up control and greater sensitivity to climate forcing. Because climate change occurs slowly, its effects are not likely to have immediate impacts on marine systems but will be manifest as the accumulation of the interactions between fishing and climate variability - unless threshold limits are exceeded. Marine resource managers need to develop approaches which maintain the resilience of individuals, populations, communities and ecosystems to the combined and interacting effects of climate and fishing. Overall, a less-heavily fished marine system, and one which shifts the focus from individual species to functional groups and fish communities, is likely to provide more stable catches with climate variability and change than would a heavily fished system.
\end{abstract}

Keywords: Climate variability; Climate change; Communities; Ecosystems; Fisheries management; Fishing; Populations 
Accepted version 2007 Sept. Journal of Marine Systems - GLOBEC Special Issue

\section{Introduction}

Variability is an inherent characteristic of marine ecosystems (e.g. Drinkwater et al., this volume). This variability is due to climate forcing, internal dynamics such as predator-prey interactions, and to anthropogenic forcing such as fishing. The latter has occurred for centuries (Jackson et al., 2001; Poulsen, this volume), but is recognised as being globally more intensive since the onset of industrial fishing in the 1950s (Pauly et al., 2002). In addition, the variability of global catches has been increasing over time (Halley and Stergiou, 2005). The challenge to modern fisheries management is to understand and take account of these sources of variability, and their interactions. The traditional goal has been to attempt to distinguish impacts due to fishing from those due to climate (e.g. Hsieh et al., 2006), with the hope that the former can be controlled whereas the latter can be observed and (possibly) predicted. Whereas fishing may dominate in some situations, in many other cases this has not been an informative approach because it is the interactions between climate and fishing which drive significant changes in exploited marine systems.

This report summarises the findings of more detailed background papers by Planque et al. (this volume), Jennings and Brander (this volume) and Brander (this volume), and the discussions of a working group held during the GLOBEC-sponsored workshop titled "Impact of Climate Variability on Marine Ecosystems: A Comparative Approach”. We explore some of the conceptual issues involved in understanding and predicting how human exploitation of marine systems modifies the responses of these systems to climate forcing. Specifically, we ask if fishing increases the sensitivity of marine systems to climate forcing. Here, we define "sensitivity" to be a measure of the strength of the relation between the biotic variable(s) and the climate variable(s) so that, for example, increasing sensitivity implies an increasing correlation between fluctuations in population abundance (or another characteristic) and some climate signal. The mechanisms by which climate variability affects marine fish populations are reviewed by other authors (e.g. Lehodey et al., 2006; Bakun, this volume; Drinkwater et al., this volume; Ottersen et al., this volume). Similarly, the environmental effects of fishing have been a popular topic over the past decade (e.g. Gislason et al., 2000). Our focus, however, 
is on the effects of fishing on the responses of marine systems to climate forcing. We also consider management approaches which may mitigate the effects of human exploitation on marine systems when climate is changing. In addition, we provide recommendations for research needed to further explore and test the hypotheses presented.

We distinguish two primary components of climate forcing of marine systems: variability, and change (trend). Climate variability occurs on a wide range of time scales (Overland et al., this volume) from seasonal periods, to 1-3 year oscillating but erratic periods (e.g. ENSO), to decadal aperiodic variability at 5-50 years, to centennial and longer periods. For the purposes of this report, we are most concerned with variability at periods equal to or less than several generations of most fish, e.g. less than 100 years. We also define climate variability to include extreme events, such as the one in one hundred year storm, that may sufficiently disrupt the system and cause it to move to a new state. Climate change (trend) is defined as the secular change which at present, in the case of temperature, appears to be increasing and largely anthropogenically-driven, and whose rate is small compared with that of the variability at the shorter time scales discussed above. Climate change may also affect climate variability, for example the frequency of El Niño or extreme events, although large uncertainties remain (e.g. Collins, 2000).

We organise our discussion around how fishing modifies the effects of climate on marine systems at the "levels" of the individual, population, community, and ecosystem. 'Population' is defined as a group of interacting and interbreeding individuals of the same species, e.g. Georges Bank herring. 'Community' is a taxonomically or functionally defined subset of animals in the ecosystem that interacts with other communities, e.g. the pelagic fish community. This definition of a community includes assemblages, since many community studies have tended to focus on species of human interest or species that can be readily sampled rather than animals that are related through function or food web interactions. The ecosystem is defined as the dynamic complex of biotic communities and their non-living environment. It is broader than the community because it is a complex consisting of multiple communities and their environments which function as a reasonably self-sustaining unit, e.g. the Georges Bank or North Sea ecosystem.

In general, it is expected that individuals, populations, communities and ecosystems will be adapted to the range of climate variability that they have experienced 
Accepted version 2007 Sept. Journal of Marine Systems - GLOBEC Special Issue

in the past. Our focus is on how fishing may affect these adaptations, in particular during a time of anticipated increases in the rate of climate change.

\section{Does fishing increase the sensitivity of individuals to climate forcing?}

The effects of climate variability and climate change are generally observed at population, community and ecosystem levels, but these are largely the outcomes of processes acting on individuals. The response of individuals to changes in their (biological, physical and chemical) environment and their ability to adapt to such changes are a necessary part of understanding and predicting responses at higher levels of organisation.

In general it is not easy to evaluate whether exploitation can alter sensitivity to climate variability and change at the individual level. Selection (both fishing selection and genetic selection) operates on individuals, but the consequences are observed in changes in the frequency of population characteristics. Fishing is unlikely, therefore, to have a strong influence on the responses of individuals to climate forcing, other than to remove individuals with certain characteristics from the gene pool thereby changing the genetic make-up of the population and the population response to climate forcing (see Section 3). An example of selection for particular kinds of behaviour (which may or may not be inherited) is the "school-mix feedback" hypothesis of Bakun (2001; see also Alheit and Bakun, this volume).

The responses of individuals can be studied experimentally and their physiology, life history, energy utilisation and behaviour provide basic explanations for observed higher level patterns. For example, a density gradient can be used to determine the level at which eggs will float in a stratified water column. In the Baltic, where salinities are low and the deeper, denser water masses are often anoxic, this information can be used to predict how egg survival may be affected by climate-induced changes in density structure and oxygenation (Nissling et al., 1998; Hinrichsen et al., 2002). Thermal tolerances of marine fishes are set by the capacities of the circulatory and respiratory systems to match 
the cellular demand for oxygen (Pörtner and Knust, 2007). As temperatures warm beyond the range of adaptation, fish will experience decreased aerobic function, leading to relocation or death. Larger individuals are likely to be more sensitive to this effect, reaching temperature-dependent aerobic limits sooner than smaller individuals (Pörtner and Knust, 2007). The limits of tolerance in relation to all relevant environmental factors (temperature, salinity, oxygen, etc) can be used to construct "bioclimate envelopes" within which the species can survive (Pearson and Dawson, 2003). The physiological bases for climate effects (via temperature, $\mathrm{CO}_{2}$ and oxygen) on marine organisms and ecosystems are reviewed by Pörtner (2006). These tolerances may define limits for predicting how individual species are likely to respond to climate trends, at least over less-than-evolutionary time scales.

Experimental studies (including large-scale field experiments) of the effects of factors which are influenced by climate are the main tool for understanding and predicting consequences of climate variability and change on agriculture (e.g. Porter and Semenov, 2005), but are rare for aquatic ecosystems and species. This is partly because it is difficult to conduct controlled experiments in marine systems. Nevertheless, there is scope for learning more from well-designed experiments and the progress of aquaculture may advance understanding.

\section{Does fishing increase the sensitivity of populations to climate forcing?}

By acting on individuals, fishing alters the characteristics of the population and changes how the population responds to climate forcing (Fig. 1). Planque et al. (this volume) review how exploitation can alter the structure of fish populations, and thereby modify their ability to respond to climate variability and change. Here, we highlight and summarise the key processes that relate to the demographic structure, spatial structure, and life history traits of fish populations and their interactions with climate forcing. In essence, fishing simplifies the characteristics of marine populations making them more sensitive to climate forcing. 
Accepted version 2007 Sept. Journal of Marine Systems - GLOBEC Special Issue

\subsection{Alteration of demographic structure}

One consequence of fishing, which is evident in almost all marine systems, is that it removes preferentially the large (older) individuals. This size-selective removal truncates the population's age structure and has several consequences.

A first consequence is a reduction in the buffering capacity of the population. Whereas a population composed of many age classes can face long periods of adverse environmental conditions (in the sense of adverse for recruitment), a population of the same species with fewer age classes may not be able to survive successive years of poor recruitment. In addition, life-cycle characteristics (i.e. longevity, age at maturity, density dependence within and between cohorts, etc.) modulate the way the environmental variability is experienced by the population. This leads to the prediction that exploited populations should exhibit greater variability. This has been observed in a comparison between exploited and unexploited fishes in the California Current System (Hsieh et al., 2006). In addition, such populations with truncated age structures should respond with greater intensity to inter-annual climate fluctuations, whereas the responses of unexploited populations or populations with many age classes may be dampened at shorter time scales but more evident at longer time scales (e.g. interdecadal).

Truncation of age structure may also lead to a change in the spawning dynamics of the population. Spawning of large/old individuals tends to be more extended seasonally and spatially than for younger spawners (e.g. Berkeley et al., 2004). In addition, egg survival appears to decrease with decreasing age of spawners. A reduced age structure may therefore lead a population to literally 'put all its eggs in the same basket' by spawning highly vulnerable eggs in a reduced time/space window (Fig. 2). This would make recruitment extremely susceptible to climate conditions at the time of spawning, hatching and larval development, therefore increasing the sensitivity of recruitment to interannual changes in climate forcing.

The conclusion is that several mechanisms can lead marine populations to become more sensitive to climate variability at interannual to interdecadal scales if their demographic structure is truncated (which is common to exploited populations). Such populations are expected to display variability at shorter time scales as their demographic structure shrinks (empirical evidence for this may be gained from paleoceanographic 
Accepted version 2007 Sept. Journal of Marine Systems - GLOBEC Special Issue

records and historical reconstructions). Similarly, it is expected that responses to extreme climate events should occur more quickly and be amplified when old individuals are under-represented in the populations.

Whether climate trends will have greater or lesser impacts on populations with truncated demography is unclear. It can be expected that if populations are able to adjust to climate variability at interannual to interdecadal scales (at which variability is greatest) they may also be able to adapt to climate trends. Threshold limits (e.g. thermal tolerances), non-linear responses, and overcompensatory population dynamics will make these patterns more complex in ways that are population-specific and therefore difficult to generalise.

\subsection{Alteration of spatial structure}

The spatial structures of marine fish populations can encompass a wide range of configurations, including patchy populations, networks, and meta-populations (sensu Kritzer and Sale, 2004). The effects of fishing may differ between sub-units of a population (when such sub-units exist), because fishing is not spatially random but targets specific locations. Asynchronous fluctuations in these population sub-units may reduce the overall effects of climate forcing when exchanges between the sub-units exist (e.g. Hilborn et al., 2003; Begg and Marteinsdóttir, 2002). Removal of sub-units by fishing is therefore expected to increase the sensitivity of the overall population to climate fluctuations at interannual to multi-decadal scales (e.g. Ottersen et al., 2006). When migration patterns of particular sub-units of a population are lost (due to overfishing or other disturbances), these patterns may not be easily restored, even if the biomass is brought back to a high level (e.g. North Sea herring, Corten, 2002). In such situations, the population response to climate forcing is expected to be modified, but the population may be more or less sensitive to climate forcing depending on the collection of sub-units that persists.

\subsection{Alteration of life-history traits}

There are several examples of trends in life history traits such as growth and ageat-maturity that have been attributed to the genetic consequences of fishing (e.g. Law 
Accepted version 2007 Sept. Journal of Marine Systems - GLOBEC Special Issue

2000) and it has been argued that these effects may become irreversible (de Roos et al., 2006). The consequence of increased growth rates and decreased age-at-maturity is to reduce its generation or replacement time. Empirical evidence suggests that fish species which exhibit faster generation times are likely to spatially redistribute faster in response to environmental change (Perry et al., 2005). If it is reasonable to extrapolate from the among-species to the within-species case, then the effect of fishing would be to accelerate the response of populations to climate forcing.

\subsection{Summary of population sensitivities}

The effects of fishing on exploited marine populations summarised here (and discussed in more detail by Planque et al., this volume) all converge towards a reduction in the diversity of demographic, spatial and temporal population characteristics. Reduction in the number of age groups is the most obvious, but spatial contraction, loss of population sub-units, or alteration of life-history traits can also be strongly driven by fishing. Simple consideration of the processes that regulate fish population dynamics suggest that all these effects may make populations more strongly connected to climate variability at interannual to interdecadal scales.

\section{Does fishing increase the sensitivity of communities to climate forcing?}

Fishing has direct effects on fish community structure since it leads to changes in the growth, mortality, and recruitment of target fish populations. However, the capture of target or by-catch species also has indirect effects, and the direct and indirect effects of fishing act in combination to determine the resulting biomass, size structure and diversity of communities. To understand how these direct and indirect consequences of fishing might affect the sensitivity of fish communities to climate forcing, it is necessary to know how marine communities are structured and to understand the effects of fishing on these structures (Jennings and Brander, this volume).

The observed diversity, range of life histories and relative abundances of species in communities reflect their past interactions with the environment and interactions with predators and competitors. When comparing unexploited communities, diversity will 
usually vary widely among ecosystems, but the distributions of sizes and life history strategies among individuals and species are often more consistent. Whereas there can be large regional variations in fish diversity (e.g. Ormond and Roberts, 1997), the relative abundance of fishes in different body size classes is remarkably consistent (Bianchi et al., 2000). The slopes of relationships between abundance and body size (size spectra) that include phytoplankton, zooplankton and fish appear to show remarkably little variation among ecosystems despite the highly variable dynamics of component species, suggesting some constancy in the underlying structuring processes (Boudreau and Dickie, 1992). In exploited fish communities, modelling studies suggest that fishing on higher trophic levels causes the slope of the size spectrum to steepen and the intercept to increase in proportion to fishing effort (Gislason and Rice, 1998). Observational studies suggest that the biomass of species within trophic guilds shows a relative stability that is not apparent in individual species, at least for the heavily exploited Georges Bank system (Duplisea and Blanchard, 2005).

There is evidence of local reductions in species richness within fish communities due to fishing, and species richness declines with fishing intensity. This has been demonstrated in comparisons between fished and unfished (marine reserve) areas and by comparing species richness across gradients of fishing effort (e.g. Gislason, 2003). In low diversity communities, fluctuations in a small number of prey species with limited functional redundancy could have profound effects on energy transfer to higher trophic levels. In other situations where functional redundancy is high, marked shifts in species composition may result in relatively little change in community properties. For example, Link and Garrison (2002) noticed a shift in the abundance and size composition of fish predators over the last four decades in the Georges Bank ecosystem, which was attributed to fishing pressure. A remarkable shift from cod to spiny dogfish was observed, but there were no apparent changes in total fish consumption by the six major predators despite changes in predator size, structure and abundance.

\subsection{Sensitivity to climate forcing}

Climate change, as defined above, occurs slowly and incrementally and is unlikely to have significant influence on the short-term responses of a fish community. In 
the life spans of most fishes, with few exceptions (Parker et al., 2000), the individual will be affected more by variability than by the trend (within tolerance limits). However, on evolutionary timescales (e.g. decades; Law, 2007), the presence of genetic diversity, manifest within and among species, is likely to increase the probability that species in the community can adapt to the physiological consequences of climate change and the changes in prey and competitors that will also occur. Given the different thermal tolerances and life histories of species in any community, the community cannot be seen as a fixed entity, and species abundances and interactions will change with the effects of climate. This is one reason why greater stability is observed when aggregating across species to examine the overall properties of the fish community, such as production or relative abundances in size-classes, than when studying single species (Duplisea and Blanchard, 2005).

Responses by fish communities to climate variability are expected to be strongly influenced by fishing (e.g. Pauly et al., 1998; Myers and Worm, 2005). The effects of fishing on communities are that the mean trophic level of the community falls, the mean size of animals in the community falls, mean turnover time increases due to the higher metabolic rates of smaller animals per unit biomass, energy is cycled faster and a greater proportion of total energy input is allocated to reproductive output. These changes are expected to alter how the community responds to climate forcing since exploited fish communities with faster mean turnover times are expected to track more closely the short-term variability in production that results from variability in climate.

\section{Does fishing increase the sensitivity of ecosystems to climate forcing?}

Marine ecosystems are composed of individuals, populations and communities that are responsive to their immediate environment, e.g. through changes in water temperature, nutrient dynamics, increased $\mathrm{CO}_{2}$ (decreased $\mathrm{pH}$ ), and changes in wind forcing and circulation patterns (Harley et al., 2006). The effects of fishing on the sensitivities of individuals, populations, and communities of fish to climate forcing have been discussed above; all of these also have important consequences on marine ecosystems. The approach that is developed here is to determine when and how some 
Accepted version 2007 Sept. Journal of Marine Systems - GLOBEC Special Issue

ecosystems can be more sensitive to climate following intense exploitation whereas other ecosystems appear to buffer those environmental changes. Despite the existence of complex trophic interactions, strong patterns emerge at the ecosystem level through the combined effects of predation (top-down control) and plankton production (bottom-up control). The balance of one type of control versus the other can be altered by exploitation.

\subsection{Predation and competition}

By removing top predators, fishing can enhance the biomass and production of species at the lower trophic levels. Worm and Myers (2003) suggested that cod predation was limiting shrimp biomass in the Northwest Atlantic, with shrimp biomass increasing significantly in the 1990s following the collapse of the cod stocks. A dominance change from a long-lived fish species (cod) to a short-lived pelagic species (sprat) occurred in the ecosystem of the central Baltic Sea. The combined effects of fishing and adverse hydrographic conditions collapsed the cod stock, reducing predation on the sprat stock which, due to bottom-up control, now dominates the system to a degree not observed previously (Köster et al., 2003). Changes such as this may not be easily reversible, because the now-dominant middle trophic level species is a predator on the early life stages of the former top predator, e.g. a prey-to-predator loop (P2P-loop, in which the prey becomes the predator; Köster and Möllmann, 2000). Another loop represents the decline of the copepod Pseudocalanus acuspes caused by the increased sprat stock (Möllmann and Köster, 2002). The low abundance of the copepod causes food-limitation and thus high mortality of cod larvae which feed to a large degree on $P$. acuspes (Hinrichsen et al., 2002, Voss et al., 2003). According to Walters and Kitchell (2001) large, dominant fish species that are the basis of many fisheries may be successful in part due to these "cultivation" effects, in which adults crop down forage species that are potential competitors/predators of their own juveniles. Fishing can also modify competitive interactions. Thus, the mass production of jellyfish in the Northern Benguela upwelling region was associated with a collapse of both anchovy and sardine populations (Cury and Shannon, 2004; Lynam et al., 2006). 
Accepted version 2007 Sept. Journal of Marine Systems - GLOBEC Special Issue

\subsection{Trophic cascades}

Ecosystems can be impacted at more than two trophic levels by trophic cascades. The collapse of top predators has recently been demonstrated to cascade down some marine food webs, a process commonly observed in freshwater systems (Cury et al., 2003). In the sub-Arctic North Pacific, inverse relationships have been found between the large pulses in abundance of planktivorous pink salmon (Oncorhynchus gorbuscha) and the biomass of its zooplankton prey, and between zooplankton and phytoplankton biomass (Shiomoto et al., 1997). Analysing the relative contribution of bottom-up versus top-down control in the Black Sea, Daskalov et al. (2007) concluded that overexploitation of large predators, such as dolphins, mackerel, bonito and bluefish, increased planktivorous fish biomass in the early 1970s, and consumption of the zooplankton increased in response (the biomass of jellyfish also increased considerably). Frank et al. (2005) provided evidence for a cascade on the eastern Scotian Shelf (NW Atlantic) that involves four trophic levels, that was driven by changes in the abundance of large predators (primarily cod) and macroinvertebrates. Trophic cascades or a drastic release of top-down effects reflect a major perturbation that is influenced by overfishing and sometimes exacerbated by environmental changes. By diminishing predation intensity on forage fish, exploitation favours the increase of these lower trophic levels. These processes may contribute to regime shifts in marine ecosystems (Cury and Shannon, 2004).

As with fish communities, top-down control mechanisms are sometimes dampened by redundant species within functional groups and complex interactions that are unfortunately rarely documented, and which can be important at modulating an ecosystem's response to climate forcing. A comparison between nine heavily fished Northwest Atlantic ecosystems revealed the importance of species diversity (redundancy between species at high trophic levels) for dampening top-down control and trophic cascades (Frank et al., 2006). A combination of population dynamics (redundancy) and accelerated demographic rates accounted for the greater stability of the predator species complex in the southern-most of these Northwest Atlantic ecosystems (Georges Bank Gulf of Maine). In addition, Frank et al. (2006) indicated that top-down control predominates in the low productivity northern systems (Labrador Shelf), whereas bottom- 
Accepted version 2007 Sept. Journal of Marine Systems - GLOBEC Special Issue

up control predominates in the higher productivity southern systems. They concluded that "among heavily exploited areas, high primary production ones with greater species diversity are most resistant to top-down effects” (Frank et al., 2006, p.9). This suggests that changes in primary production driven by climate change (e.g. Sarmiento et al., 2004) may alter the responses of marine ecosystems to exploitation.

\subsection{Biodiversity}

Biodiversity is hypothesized to be a major determinant of ecosystem stability (e.g. Hooper et al., 2005). Top predators can act as couplers of distinct energy channels that differ in both productivity and turnover rate. Removing top predators by fishing can therefore modify ecosystem structures and lead to instability of the ecosystem (Rooney et al., 2006). Stability is favoured by top-down control operating by means of multiple and weak trophic interactions between species (Shin and Cury, 2001; Rooney et. al., 2006). Multiple weak interactions may stabilize ecosystems by dampening oscillations caused by strongly interacting species (Polunin and Pinnegar, 2002; Rooney et al., 2006). Retrospective and comparative studies have shown that extirpating top predator species can lead to a simplification of food-webs and alteration of their overall resilience to perturbations (Jackson et al., 2001; Balvanera et al., 2006).

\subsection{Summary of ecosystem sensitivities}

In summary, ecosystems under intense exploitation are likely to evolve towards stronger bottom-up control. Exploitation leads to a decrease in stock sizes of top predators, which are hypothesised to (i) reverse the control structure in top-down systems to bottom-up control, and (ii) amplify the control in already bottom-up controlled systems. In both types of systems this would lead to much greater vulnerability of the ecosystem to climate forcing (Fig. 3). Exploitation can also lead to simplifications of the structure of ecosystems by removing top predators and decreasing intraspecific and interspecific diversity. Top predators which regulate fish communities in marine ecosystems dampen their variability, and when top marine predators become depleted, short-lived prey populations with rapid turn-over rates can increase in biomass and fluctuate under the influence of bottom-up (climate) forcing. Fisheries can therefore bring 
Accepted version 2007 Sept. Journal of Marine Systems - GLOBEC Special Issue

ecosystems into states that are more sensitive to climate variability. The proportion of pelagic fish species in the total world fish catch has almost doubled during the last thirty years, which has been interpreted in several regions as a combination of the release of predation and environmental effects (Caddy and Garibaldi, 2000).

\section{Research and management issues and opportunities}

\subsection{Research needs}

Our thesis is that fishing can modify the responses of marine systems to climate variability and change. It is, therefore, the interactions between fishing and climate forcing of individual animals to marine ecosystems that are the crucial processes rather than the effects of fishing or climate taken separately. There are two obvious approaches to the study of these interactions: 1) "additive", in which the effects of climate and fishing are studied separately in order to understand their additive interactions; and 2) "multiplicative", in which the synergistic effects of fishing and climate are studied together to understand their complex interactions. This second approach can be separated into "inverse" and "forward" approaches. The former starts with the observed changes and works backwards, often using statistical methods, to disaggregate the roles played by climate and fishing. Drinkwater's (2002) review of the roles played by climate and fishing in the decline of northern cod provides an example. This approach may perhaps be most beneficial when used in a comparative framework with populations which have experienced different intensities of either climate forcing or fishing pressure. The "forward" approach uses a modelling framework which introduces individual effects, such as temperature on metabolism and growth versus fishing effects on mortality, to examine the complexities of the interactions and why they cannot be detected with simple correlative methods. Such models may become too complex for meaningful interpretation (of cause and effect) when constructed for the level of entire ecosystems and may therefore be more useful for single populations or fish communities. This also implies that 'simple' nutrient-phytoplankton-zooplankton-fish model approaches (e.g. deYoung

et al., 2005) which do not consider the effects of exploitation and can not resolve key climate-fishing interactions, may not adequately reproduce observed changes in marine 
systems because of the non-linearities and alterations in system structure that are induced by exploitation.

For both approaches, key unknowns for most marine species are their essential habitat requirements, tolerances for extreme ranges of temperature, salinity, and oxygen, and the extent of their local movements. In particular, the variability of these characteristics within marine populations is almost completely unknown. Determining “bioclimate envelopes” (Section 2), and the range of variability within populations, will provide the information to predict responses to climate forcing when those responses are additive (e.g. among individuals, populations, and communities). The extent of daily movements (and straying rates during migrations), in particular for young fish, are also poorly known but are key characteristics that allow populations to discover and colonise new habitats as old ones (or sub-populations) are destroyed by fishing or climate change. Migration patterns themselves may be influenced by food abundance and genetic orientation mechanisms which improve with age through experience and learning (Kvamme et al., 2003). This suggests that climate (by influencing food abundance) and fishing (by influencing age structure) may have significant interacting effects on migration route fidelity, potential for recovery of collapsed populations and colonisation of new habitats.

The extent of climate impacts on marine ecosystems depends on the structure of the system, for example less diversified systems appear to be more sensitive to climate forcing compared with more diversified systems. It is unclear, however, whether some systems may be more susceptible to the interactions of fishing and climate forcing. High latitude systems composed of long-lived species are generally thought to be resilient to high frequency variability, to vary slowly, and therefore to be more stable than low latitude upwelling systems. These latter systems are generally thought to vary at higher frequencies, for example in response to ENSO events (although there is debate about the time scale of responses to ENSO; Barber, 2001). Both types of systems are heavily fished and both have experienced strong changes and collapses in recent years (e.g. Frank et al., 2006; Lynam et al. 2006). Comparisons among diverse ecosystems with different climate and fishing histories should help to elucidate general principles concerning these interactions. Fragility of components of the system, for example how close a key species 
Accepted version 2007 Sept. Journal of Marine Systems - GLOBEC Special Issue

might be to a detrimental physical or biological threshold (e.g. temperature limitation of corals in reef systems; Hughes et al., 2003; Graham et al. 2006), may also dominate the anticipated general response of ecosystems to climate variability and change. The possibility exists for catastrophic changes in marine ecosystems resulting from apparently small perturbations, as has been observed for coral reef and North Pacific marine systems (e.g. Scheffer et al., 2001).

\subsection{Management approaches and predictability}

Studies over the past ten years on the ecosystem effects of fishing (broadly stated) have increased awareness of the many ways that fishing can modify marine populations and ecosystems. Gislason et al. (2000) proposed six conservation objectives to control the impacts of fishing on marine environments, viz, maintenance of: ecosystem diversity, species diversity, genetic variability within species, directly-impacted species, ecologically-dependent species, and trophic level balance. Achievement of these objectives would also maintain the range of abilities of individuals, populations, communities, and ecosystems to respond to climate variability and adapt to climate change (King, 2005; Planque et al., this volume). Loss of biodiversity, including depleting large individuals and top predators, extirpating genetically distinct population sub-units, losing the spatial patterns of these sub-units, and increasing the overall level of fishing mortality, are key factors which can cause marine systems to be more strongly correlated with, and respond more quickly to, climate variability.

Setting biological reference points for fish stocks is based on current and historical characteristics such as population growth rates and stock-recruitment relationships (Brander, this volume). If fishing increases the correlation, and decreases response times, of marine systems to climate forcing, then past system performance may be a poor indicator of appropriate future reference points. This increases the uncertainties in assessments and puts pressure on marine resource managers to monitor more intensively and respond more quickly to changes in stock trajectories or productivity conditions. King and McFarlane (2006) outline a framework to incorporate climate into ecosystem productivity and fisheries management which includes ecosystem (climate) assessment, risk analysis, adaptive management, and reference points tuned to 
productivity regimes. Their simulations suggest that prediction of climate variability (regime shifts in their study) is not necessary, but that rapid identification of shifts after they have occurred is important. Use of indicators which identify changes in marine systems due to fishing that align these systems more closely with climate forcing, such as changes in age-at-maturity (e.g. de Roos et al., 2006), may also provide rapid information on population stress (e.g. Trippel, 1995). New management approaches which shift the focus from conservation of targeted (commercial) species to functional groups that support essential processes and ecosystem services (e.g. Hughes et al., 2003) may also be appropriate for managing the joint effects of fishing and climate. The constraints placed on the structure of fish communities by predator and prey size relationships and trophic transfer efficiencies (Section 4) suggest that the overall productivity of fish communities, but not their species compositions, may be predictable. Management should respond by adjusting the overall fishing capacity to match overall fish community productivity, but allowing flexibility among the particular species caught, since predictability of individual species abundances may be low (Jennings and Brander, this volume).

Fisheries management, and commercial and artisanal fishing operations, prefer situations with reduced uncertainty, i.e., that are predictable. Predictability can be considered from three perspectives. First, from the perspective of fishers, predictability tends to be synonymous with stability of catch, in which a relatively stable and expected catch can be taken from year to year. Second, from the perspective of the fishery scientist, predictability might mean that catches can be predicted a few years into the future because most of the biomass and potential yield is in age classes that have already recruited and therefore can be assessed. Third, from the perspective of a scientist assessing climate affects on ecosystems, predictability might mean that the response of a given component or attribute of the ecosystem closely tracks climate and can therefore be predicted from the climate signal. These distinctions are important. Predictability based on stability (perspectives one and two) is likely to be achieved by minimising fishing impacts on the system. Predictability based on closely tracking climate change (perspective three), however, is likely to increase as a community is more heavily exploited because the dynamics of the component species would then track the climate signal more closely. 
Accepted version 2007 Sept. Journal of Marine Systems - GLOBEC Special Issue

The stability of aggregate fisheries yield from the system is important for people in countries with a high dependence on fish production for protein, but fisheries yield from individual species can be critical when markets and industry depend on these species. Total productivity of a fish community is more stable than the productivity of individual species, but for fisheries to benefit from this community stability it is necessary that the fisheries are sufficiently flexible to respond to the changing fishing opportunities. Often, small-scale and inshore fisheries are well-adapted to change because they already have to be flexible in order to maintain some catches from the same area despite marked seasonal variations in the available fish. Many larger offshore fisheries, conversely, may be less flexible in the range of species they can catch, but can compensate for this because they have the capacity to move between regions and ecosystems. A less heavily fished marine system is likely to provide more stable catches even under conditions of climate variability and change. Stability of catch for the fishery during climate change can further be assured if the fishery is permitted to catch a greater diversity of species.

\section{From climate-or-fisheries to climate-and-fisheries}

The foregoing has outlined concepts of how fisheries can alter the sensitivities of individuals, populations, fish communities, and entire marine ecosystems to climate forcing. We conclude that exploitation impacts the sensitivity of individual fish to climate forcing by removing individuals (often those with specific characteristics) and altering the genetic composition and variability within the population. The impacts of these alterations then affect the ability and range of options available to populations, communities, and ultimately ecosystems to respond to climate forcing. Whereas the responses of fish populations and communities to climate and exploitation can largely be viewed as the sum of their parts, marine ecosystems have complex and emergent properties, for example related to spatial heterogeneity and food web processes, that complicate prediction of their responses to the interactions of these drivers of change (e.g. Frank et al., 2006). 
Accepted version 2007 Sept. Journal of Marine Systems - GLOBEC Special Issue

Climate forcing can be separated into two main components: climate variability (here including extreme events), and climate trends or change (Section 1). We conclude that exploitation increases the sensitivity of marine systems to climate variability, since this is what is experienced at space and time scales relevant to individual ambits and lifespans. Climate change occurs sufficiently slowly relative to the life spans of most marine species that it is unlikely to have an immediate (i.e. at any specific time) impact on marine systems - unless a critical threshold for one or more species is exceeded (e.g. Durant et al., 2007). Decadal time scales may also be required for evolutionary changes from fishing to become apparent (Law, 2007). Rather, the effects of climate change are experienced as an accumulation of the effects of climate variability, including rapid changes such as regime shifts (which we consider an example of extreme events). Therefore, improved understanding of the processes by which human exploitation alters the sensitivity of marine systems to climate variability will also help us to understand the sensitivity of marine systems to climate change. Management needs to develop approaches which maintain the resilience of individuals, populations, communities of fish, and marine ecosystems, to these combined and interacting effects of climate and fishing.

\section{Acknowledgements}

We thank GLOBEC and EUR-OCEANS for travel support for participants to the workshop on the "Impact of Climate Variability on Marine Ecosystems: A Comparative Approach”. P.C. acknowledges the European Network of Excellence for Oceans Ecosystem Analysis (EUR-OCEANS; www.eur-oceans.eu) and the French ANR 'Chaloupe' program for providing scientific funds. We thank Ken Drinkwater, Mikko Heino, and an anonymous reviewer for their comments on the manuscript. 
Accepted version 2007 Sept. Journal of Marine Systems - GLOBEC Special Issue

\section{References}

Alheit, J. and Bakun, A. Population synchronies within and between ocean basins: apparent teleconnections and implications as to physical-biological linkage mechanisms. J. Mar. Syst., (this volume).

Balvanera, P., Pfisterer, A.B., Buchmann, N., He, J.-S., Nakashizuka, T., Raffaelli, D. and Schmid. B. 2006. Quantifying the evidence for biodiversity effects on ecosystem functioning and services. Ecol. Lett. 9, 1-11

Bakun, A. 2001. 'School-mix feedback': a different way to think about low frequency variability in large mobile fish populations. Prog. Oceanogr. 49, 485-511.

Bakun, A., Linking climate to population variability in marine ecosystems characterized by non-simple dynamics: conceptual templates and schematic constructs. J. Mar. Syst. (this volume).

Barber, R. 2001. Upwelling ecosystems. In: .Steele, J.H., Thorpe, S.A., and Turekian, K.K. (Eds.), Encyclopedia of Ocean Sciences. Academic Press, London, pp. 31283135.

Begg, G. A., and Marteinsdóttir, G. 2002. Environmental and stock effects on spawning origins and recruitment of cod Gadus morhua. Mar. Ecol. Prog. Ser. 229, 245-262.

Berkeley, S.A., Hixon, M.A., Larson, R.J. and Love, M.S., 2004. Fisheries sustainability via protection of age structure and spatial distribution of fish populations. Fisheries 29(8), 23-32.

Bianchi, G., Gislason, H., Graham, K., Hill, L., Jin, X., Koranteng, K., ManickchandHeileman, S., Paya, I., Sainsbury, K., Sanchez, F. and Zwanenburg, K. (2000) Impact of fishing on size composition and diversity of demersal fish communities. ICES J. Mar. Sci. 57, 558-71.

Boudreau, P.R. and Dickie, L.M. 1992. Biomass spectra of aquatic ecosystems in relation to fisheries yield. Can. J. Fish. Aquat. Sci. 49, 1528-1538.

Brander, K.M. Impacts of climate change on fisheries. J. Mar. Syst. (this volume). 
Accepted version 2007 Sept. Journal of Marine Systems - GLOBEC Special Issue

Caddy, J.F. and Garibaldi, L.. 2000. Apparent changes in the trophic composition of world marine harvests: The perspective from the FAO capture database. Ocean Coastal Manag. 43, 615-655.

Collins, M. 2000. Understanding the uncertainties in the response of ENSO to greenhouse warming. Geophys. Res. Lett. 27, 3509-3512.

Corten, A., 2002. The role of "conservatism" in herring migrations. Rev. Fish Biol. Fisheries 11, 339-361.

Cury, P. and Shannon, L.J., 2004. Regime shifts in upwelling ecosystems: observed changes and possible mechanisms in the northern and southern Benguela. Prog. Oceanogr. 60, 223-243.

Cury P., Shannon, L. and Shin, Y.-J. 2003. The functioning of marine ecosystems: a fisheries perspective. In: M. Sinclair and G. Valdimarsson (Eds), Responsible Fisheries in the Marine Ecosystem. CAB International, Wallingford, pp: 103-123.

Daskalov, G.M., Grishin, A.N., Rodionov, S. and Mihneva, V. 2007. Trophic cascades triggered by overfishing reveal possible mechanisms of ecosystem regime shifts. PNAS 104, 10518-10523

de Roos, A.M., Boukal, D.S. and Persson, L., 2006. Evolutionary regime shifts in age and size at maturation of exploited fish stocks. Proc. Royal Soc.Lond. B 273(1596), 1873-1880.

deYoung, B., Heath, M., Werner, F., Chai, F., Megrey, B., Monfray, P. 2004. Challenges of modeling ocean basin ecosystems. Science 304,:1463-1466.

Drinkwater, K.F. 2002. A review of the role of climate variability in the decline of northern cod. In: N.A. McGinn (Ed.), Fisheries in a changing climate. The American Fisheries Society, Bethesda, Maryland, pp. 113-129.

Drinkwater, K.F., Beaugrand, G., Kaeriyama, M., Kim, S., Ottersen, G., Perry, R.I., Pörtner, H.-O., Polovina, J. and Takasuka, A. 2007. On the mechanisms linking climate to ecosystem changes. J. Mar. Syst. (This Volume) 
Accepted version 2007 Sept. Journal of Marine Systems - GLOBEC Special Issue

Duplisea, D.E. and Blanchard, F. 2005. Relating species and community dynamics in an heavily exploited marine fish community. Ecosystems 8, 899-910.

Durant, J.M., Hjermann, D. Ø., Ottersen, G. and Stenseth, N. Chr. 2007. Climate and the match or mismatch between predator requirements and resource availability. Climate Res. 33, 271-283.

Frank, K.T., Petrie, B., Choi, J.S., and Leggett, W.C. 2005. Trophic cascades in a formerly cod-dominated ecosystem. Science 308, 1621-1623.

Frank K.T., Petrie, B., Shackell, N.L., Choi, J.S. 2006. Reconciling differences in trophic control in mid-latitude marine ecosystems. Ecol. Lett. 9, 1-10.

Gislason, H. 2003. The effects of fishing on non-target species and ecosystem structure and function. In: M. Sinclair, M. and G. Valdimarsson (Eds), Responsible fisheries in the marine ecosystem. CAB International, Wallingford, pp. 255-274.

Gislason, H. and Rice, J. 1998. Modelling the response of size and diversity spectra of fish assemblages to changes in exploitation. ICES. J. Mar. Sci. 55, 362-370.

Gislason, H., Sinclair, M., Sainsbury, K., and O’Boyle, R. 2000. Symposium overview: incorporating ecosystem objectives within fisheries management. ICES. J. Mar. Sci. 57, 468-475.

Graham, N.A.J., Wilson, S.K., Jennings, S., Polunin, N.V.C., Bijoux, J.P. and Robinson, J. 2006. Dynamic fragility of oceanic coral reef ecosystems. PNAS 103, 8425-8429.

Halley J.M. and Stergiou, K. 2005. The implications of increasing variability of fish landings. Fish and Fisheries 6, 266-276.

Harley, C.D.G., Hughes, A.R., Hultgren, K.M., Miner, B.G., Sorte, C.J.B., Thornber, C.S., Rodriguez, L.F., Tomanek, L., and Williams, S.L. 2006. The impacts of climate change in coastal marine Systems. Ecol. Lett. 9, 228-241.

Hilborn, R., Quinn, T.P., Schindler, D.E. and Rogers, D.E., 2003. Biocomplexity and fisheries sustainability. PNAS 100(11), 6564-6568.

Hinrichsen, H. H., St John, M. A., Lehmann, A., MacKenzie, B. R., and Köster, F. W. 2002. Resolving the impact of physical forcing variations on the eastern Baltic cod 
Accepted version 2007 Sept. Journal of Marine Systems - GLOBEC Special Issue

spawning environment. ICES J. Mar. Sci. 32, 281-294.

Hooper, D.U., Chapin, F.S. III, Ewel, J.J., Hector, A., Inchausti, P., Lavorel, S., Lawton, J.H., Lodge, D.M., Loreau, M., Naeem, S., Schmid, B., Setälä, H., Symstad, A.J., Vandermeer, J. and Wardle, D.A. 2005. Effects of biodiversity on ecosystem functioning: a consensus of current knowledge. Ecol. Monogr. 75, 3-35.

Hsieh, C.-H., Reiss, C.S., Hunter, J.R., Beddington, J.R., May. R.M. and Sugihara, G. 2006. Fishing elevates variability in the abundance of exploited species. Nature 443, 859-862.

Hughes T. P., Baird, A.H., Bellwood, D.R., Card, M., Connolly, M.R., Folke, C., Grosberg, R., Hoegh-Guldberg, O., Jackson, J.B.C., Kleypas,J., Lough, J.M., Marshall, P., Nyström, M., Palumbi, S.R., Pandolfi, J.M., Rosen, B., Roughgarden, J. 2003. Climate change, human impacts, and the resilience of coral reefs. Science 301, 929-933.

Jackson, J. B. C. and 18 co-authors. 2001. Historical overfishing and the recent collapse of coastal ecosystems. Science 293, 629-638.

Jennings, S. and Brander, K. 2007. Predicting the effects of climate variation and change on marine communities and the consequences for fisheries. J. Mar. Syst. (this volume)

King, J.R. (Ed). 2005. Report of the Study Group on Fisheries and Ecosystem responses to Recent Regime Shifts. PICES Scientific Report No. 28, 162pp.

King, J.R. and McFarlane, G.A. 2006. A framework for incorporating climate regime shifts into the management of marine resources. Fish. Manag. Ecol. 13, 93-102.

Köster, F. W., Hinrichsen, H. H., Schnack, D., St John, M. A., MacKenzie, B. R., Tomkiewicz, J., Möllmann, C., Kraus, G., Plikshs, M., Makarchouk, A., and Aro, E. 2003. Recruitment of Baltic cod and sprat stocks: identification of critical life stages and incorporation of environmental variability into stock-recruitment relationships. Sci. Mar. 67 (Suppl. 1), 129-154.

Köster, F. W., and Möllmann, C. 2000. Trophodynamic control by clupeid predators on recruitment success in Baltic cod? ICES J. Mar. Sci. 57, 310-323. 
Accepted version 2007 Sept. Journal of Marine Systems - GLOBEC Special Issue

Kritzer, J.P. and Sale, P.F., 2004. Metapopulation ecology in the sea: from Levins' model to marine ecology and fisheries science. Fish and Fisheries 5, 131-140.

Kvamme, C., Nøttestad, L., Fernö, A., Misund, O.A., Dommasnes, A., Axelsen, B.E., Dalpadado, P. and Melle, W. 2003. Migration patterns in Norwegian springspawning herring: why young fish swim away from the wintering area in late summer. Mar. Ecol. Prog. Ser. 247, 197-210.

Law, R. 2000. Fishing, selection, and phenotypic evolution. ICES J. Mar. Sci. 57, 659668.

Law, R. 2007. Fisheries-induced evolution: present status and future directions. Mar. Ecol. Prog. Ser. 335, 271-277.

Lehodey, P., Alheit, J., Barange, M., Baumgartner, T., Beaugrand, G., Drinkwater, K., Fromentin, J.-M., Hare, S., Ottersen, G., Perry, R.I., Roy, C., van der Lingen, C.D., and Werner, F. 2006. Climate variability, fish and fisheries. J. Climate 19, 50095030 .

Link, J.S. and Garrison, L.P. 2002. Changes in piscivory associated with fishing induced changes to the finfish community on Georges Bank. Fish. Res. 55, 71-86.

Lynam, C.P., Gibbons, M.J., Axelsen, B.E., Sparks, C.A.J., Coetzee, J., Heywood, B.G. and Brierley, A.S. 2006. Jellyfish overtake fish in a heavily fished ecosystem. Current Biol. 16, R492-R493.

Möllmann, C. and Köster, F.W. 2002. Population dynamics of calanoid copepods and the implications of their predation by clupeid fish in the Central Baltic Sea. J. Plankton Res. 24, 959-978.

Myers, R.A. and Worm, B. 2005. Extinction, survival or recovery of large predatory fishes. Phil. Trans. Roy. Soc. Lond. B 360, 13-20.

Nissling, A., Larsson, R., Vallin, L., and Frohlund, K. 1998. Assessment of egg and larval viability in cod, Gadus morhua - methods and results from an experimental study. Fish. Res. 38, 169-186. 
Accepted version 2007 Sept. Journal of Marine Systems - GLOBEC Special Issue

Ormond, R.F.G. and Roberts, C.M. 1997. The biodiversity of coral reef fishes. In Gage, J.D. and Angel, M.D. (Eds) Marine biodiversity: patterns and processes. Cambridge University Press, Cambridge , pp. 216-257.

Ottersen, G., Hjermann, D. Ø., and Stenseth, N. C. 2006. Changes in spawning stock structure strengthen the link between climate and recruitment in a heavily fished cod (Gadus morhua) stock. Fish. Oceanogr. 15, 230-243.

Ottersen, G., Kim, S., Huse, G., Polovina, J.J. and Stenseth, N. Chr. Major routes by which climate may force marine fish populations. J. Mar. Syst. (this volume).

Overland, J., Alheit, J., Bakun, A., Hurrell, J., Mackas, D., and Miller, A. Climate controls on marine ecosystems and fisheries, J. Mar. Syst (this volume).

Parker, S.J., Berkeley, S.A., Golden, J.T., Gunderson, G.R., Heifetz, J., Hixon, M.A., Larson, R., Leaman, B.M., Love, M.S., Musick, J.A., O'Connell, V.M., Ralston, S., Weeks, H.J. and Yoklavich, M.M. (2000) Management of Pacific rockfish. Fisheries 25(3), 22-30.

Pauly, D., Christensen, V., Dalsgaard, J., Froese, R. and Torres, F., Jr. 1998. Fishing down marine food webs. Science 279, 860-863.

Pauly, D., Christensen, V., Guénette, S., Pitcher, T.J., Sumaila, U.R., Walters, C.J., Watson, R. and Zeller, D. 2002. Towards sustainability in world fisheries. Nature 418, 689-695.

Pearson, R. G., and Dawson, T. P. 2003. Predicting the impacts of climate change on the distribution of species: are bioclimate envelope models useful? Global Ecol. Biogeogr.12, 361-371.

Perry, A.L., Low, P.J., Ellis, J.R. and Reynolds, J.D., 2005. Climate change and distribution shifts in marine species. Science 308, 1912-1915.

Planque, B., Fromentin, J.-M., Cury, P., Drinkwater, K., Jennings, S., Kifani, S, and Perry, R.I. How does fishing alter marine populations and ecosystems sensitivity to climate? J. Mar. Syst. (this volume).

Polunin, N.V.C. and J.K. Pinnegar. 2002. Trophic ecology and the structure of marine 
Accepted version 2007 Sept. Journal of Marine Systems - GLOBEC Special Issue

food webs. In P.J.B. Hart and J.C. Reynolds (eds.), Handbook of Fish and Fisheries, Volume I. Blackwell,Oxford., pp. 310-320

Porter, J. R., and Semenov, M. A. 2005. Crop responses to climatic variation. Phil. Trans. R. Soc. Lond. B 360, 2021-2035.

Pörtner, H-O 2006. Auswirkungen von CO2-Eintrag und Temperaturerhöhung auf die marine Biosphäre. Report for the German Advisory Council on Global Change. http://www.wbgu.de/wbgu_sn2006_ex04.pdf

Pörtner, H.O. and Knust, R. 2007. Climate change affects marine fishes through the oxygen limitation of thermal tolerance. Science 315, 95-97.

Poulsen, B. Historical evidence for the variability of fish populations prior to industrialized fishing. J. Mar. Syst. (this volume)

Rooney, N., McCann, K., Gellner, G. and Moore, J.C., 2006. Structural asymmetry and the stability of diverse food webs. Nature 442, 265-268.

Sarmiento, J.L., Slater, R., Barber, R., Bopp, L., Doney, S.C., Hirst, A.C., Kleypas, J., Matear, R., Mikolajewicz, U., Monfray, P., Soldatov, V., Spall, S.A. and Stouffer, R. 2004. Response of ocean ecosystems to climate warming. Glob. Biogeochem. Cycles 18, GB3003, doi: 10.1029/2003GB002134, 23pp.

Scheffer, M., Carpenter, S., Foley, J.A., Folke, C. and Walker, B. 2001. Catastrophic shifts in ecosystems. Nature 413, 591-596.

Shin, Y.-J. and Cury, P. 2001. Exploring fish community dynamics through sizedependent trophic interactions using a spatialized individual-based model. Aquat. Liv. Res. 14, 65-80.

Shiomoto, A., Tadokoro, K., Nagasawa, K., and Ishida, Y. 1997. Trophic relations in the subarctic North Pacific ecosystem: possible feeding effect from pink salmon. Mar. Ecol. Prog. Ser. 150, 75-85.

Trippel, E.A. 1995. Age at maturity as stress indicator in fisheries. BioScience 45, 759771. 
Accepted version 2007 Sept. Journal of Marine Systems - GLOBEC Special Issue

Voss, R., Köster, F.W., Dickmann, M. 2003. Comparing the feeding habits of cooccurring sprat (Sprattus sprattus) and cod (Gadus morhua) larvae in the Bornholm Basin, Baltic Sea. Fish. Res. 63, 97-111.

Walters, C. and Kitchell, J.F. 2001. Cultivation/depensation effects on juvenile survival and recruitment: implications for the theory of fishing. Can. J. Fish. Aquat. Sci. 58, 39-50.

Worm, B. and Myers, R.A. 2003. Meta-analysis of cod-shrimp interactions reveals topdown control in oceanic food webs. Ecology 84, 162-173. 
Accepted version 2007 Sept. Journal of Marine Systems - GLOBEC Special Issue

\section{Figure captions}

Figure 1. A schematic representation of increased correlation of a marine population (e.g. abundance) to climate forcing when under exploitation. Temporal variations in climate (left) force a marine population which has a specific configuration (middle-top) and ultimately results in the population displaying temporal variability (right-top). The effect of fishing is to modify the structure of the marine population, for example by reducing its demographic, spatial, and temporal diversity (middle). The expected effect is an amplification of the variability of the population and closer tracking of the climate forcing (right-bottom).

Figure 2. Effect of truncated age/size structure on recruitment. The spatial and temporal extent of spawning (x-axis) varies as a function of spawner age/size. Multiple climatedriven environmental situations can be experienced by early life stages (arrowheads along the bottom axis). The reduction in the number of age/size groups leads to a reduction in spawning intensity, duration and spatial extent, leading the population to literally "put all its eggs in the same basket". The net effect is a greater sensitivity of recruitment to climate forcing.

Figure 3. Schematic illustrating expected responses of unexploited and exploited simplified marine ecosystems to climate forcing. Left side shows an unexploited ecosystem with multiple high trophic level species which have large abundances (top left) supported by several mid-trophic level species with large and small abundances (middle left), and how their aggregate biomasses vary through time (bottom left). The right side illustrates how that same climate forcing is experienced by an ecosystem which has been exploited. The number and abundances of the high trophic level species have decreased (top right), and the mid-trophic level has been simplified to a smaller number of species but with larger abundances (middle right). The aggregate biomass of these mid-trophic levels now tracks the climate forcing more closely, whereas the high trophic levels decline in abundance due to exploitation (bottom right). 


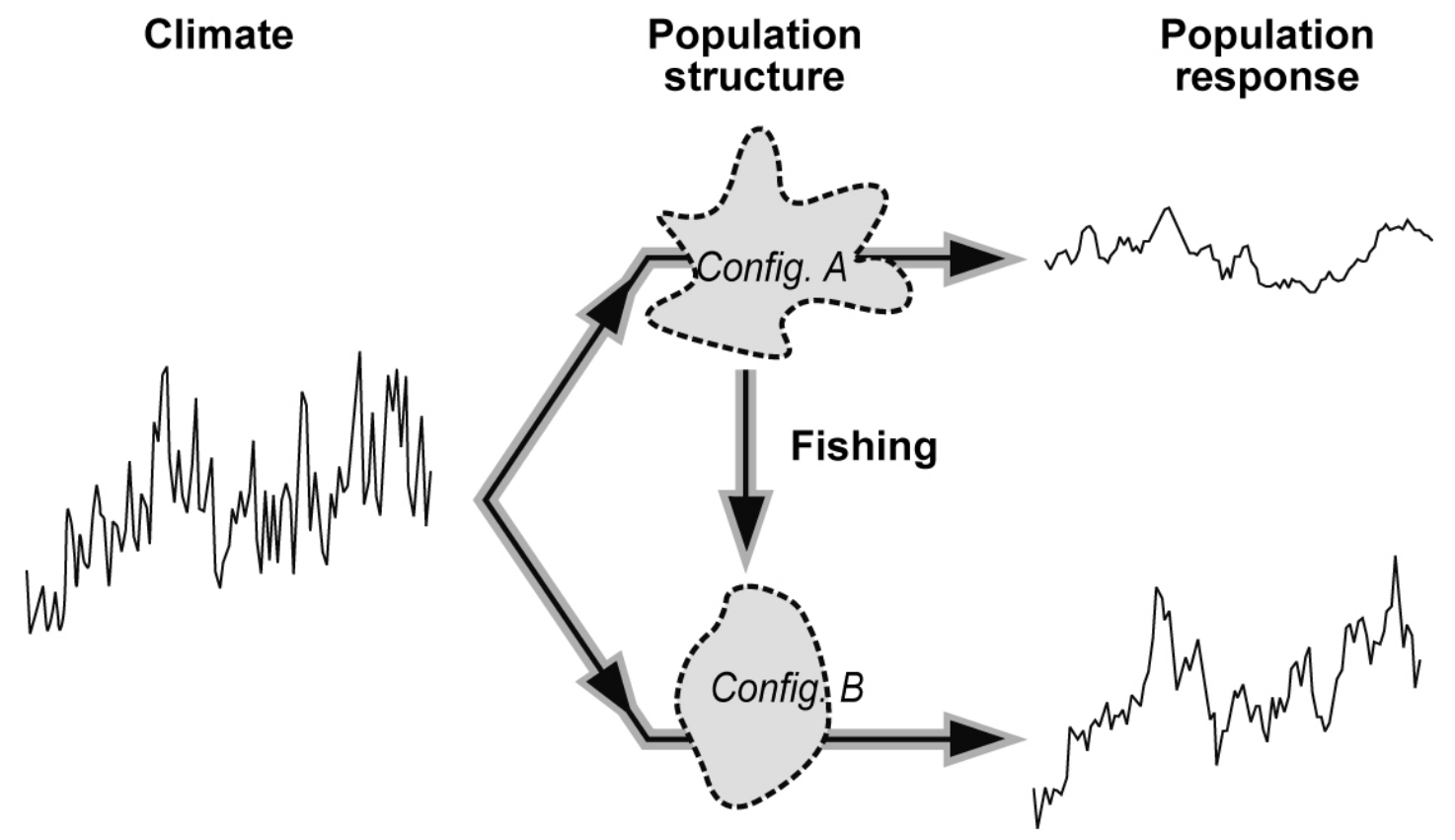

Figure 1. A schematic representation of increased correlation of a marine population (e.g. abundance) to climate forcing when under exploitation. Temporal variations in climate (left) force a marine population which has a specific configuration (middle-top) and ultimately results in the population displaying temporal variability (right-top). The effect of fishing is to modify the structure of the marine population, for example by reducing its demographic, spatial, and temporal diversity (middle). The expected effect is an amplification of the variability of the population and closer tracking of the climate forcing (right-bottom). 


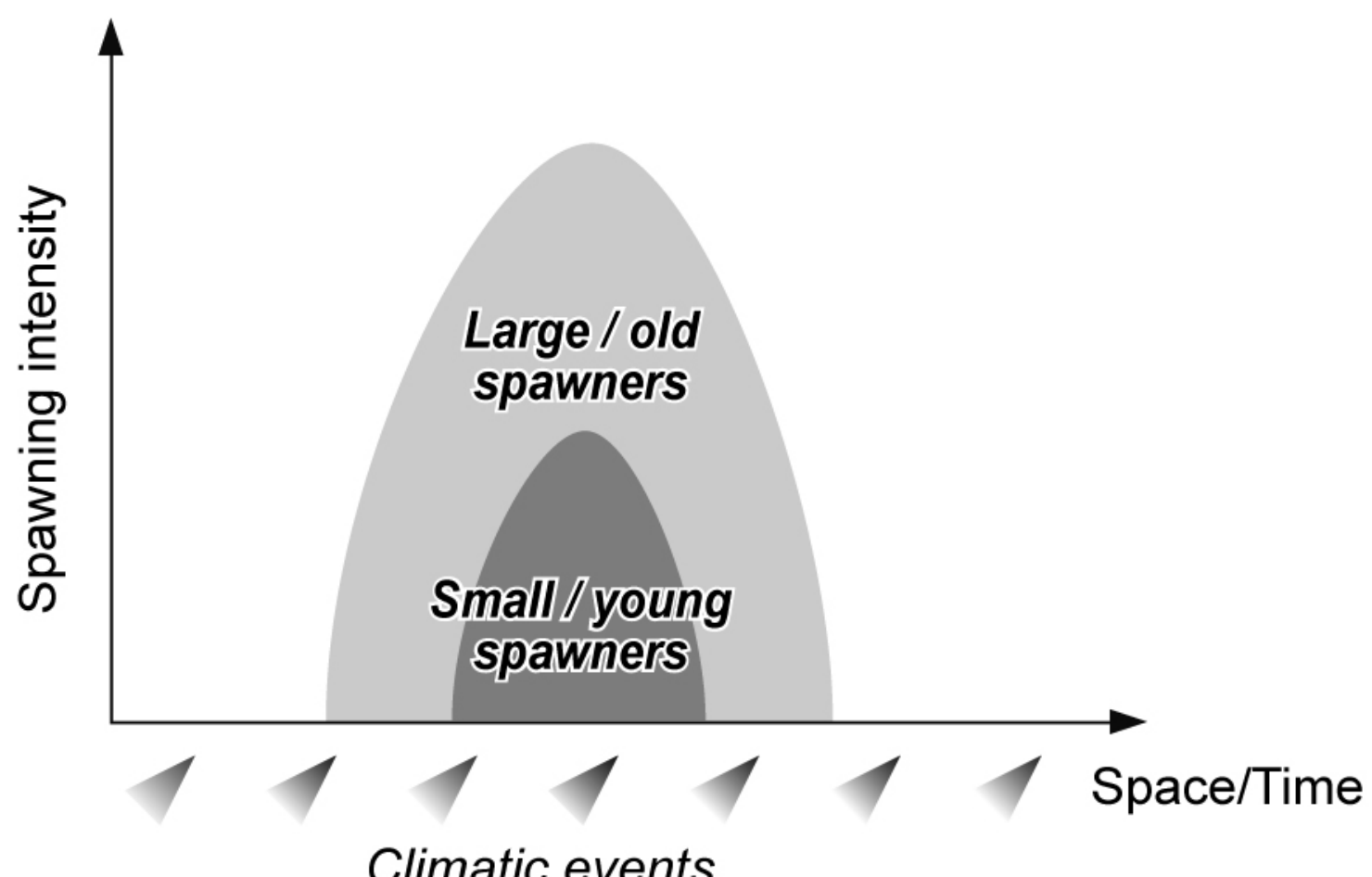

Figure 2. Effect of truncated age/size structure on recruitment. The spatial and temporal extent of spawning (x-axis) varies as a function of spawner age/size. Multiple climatedriven environmental situations can be experienced by early life stages (arrowheads along the bottom axis). The reduction in the number of age/size groups leads to a reduction in spawning intensity, duration and spatial extent, leading the population to literally "put all its eggs in the same basket". The net effect is a greater sensitivity of recruitment to climate forcing. 


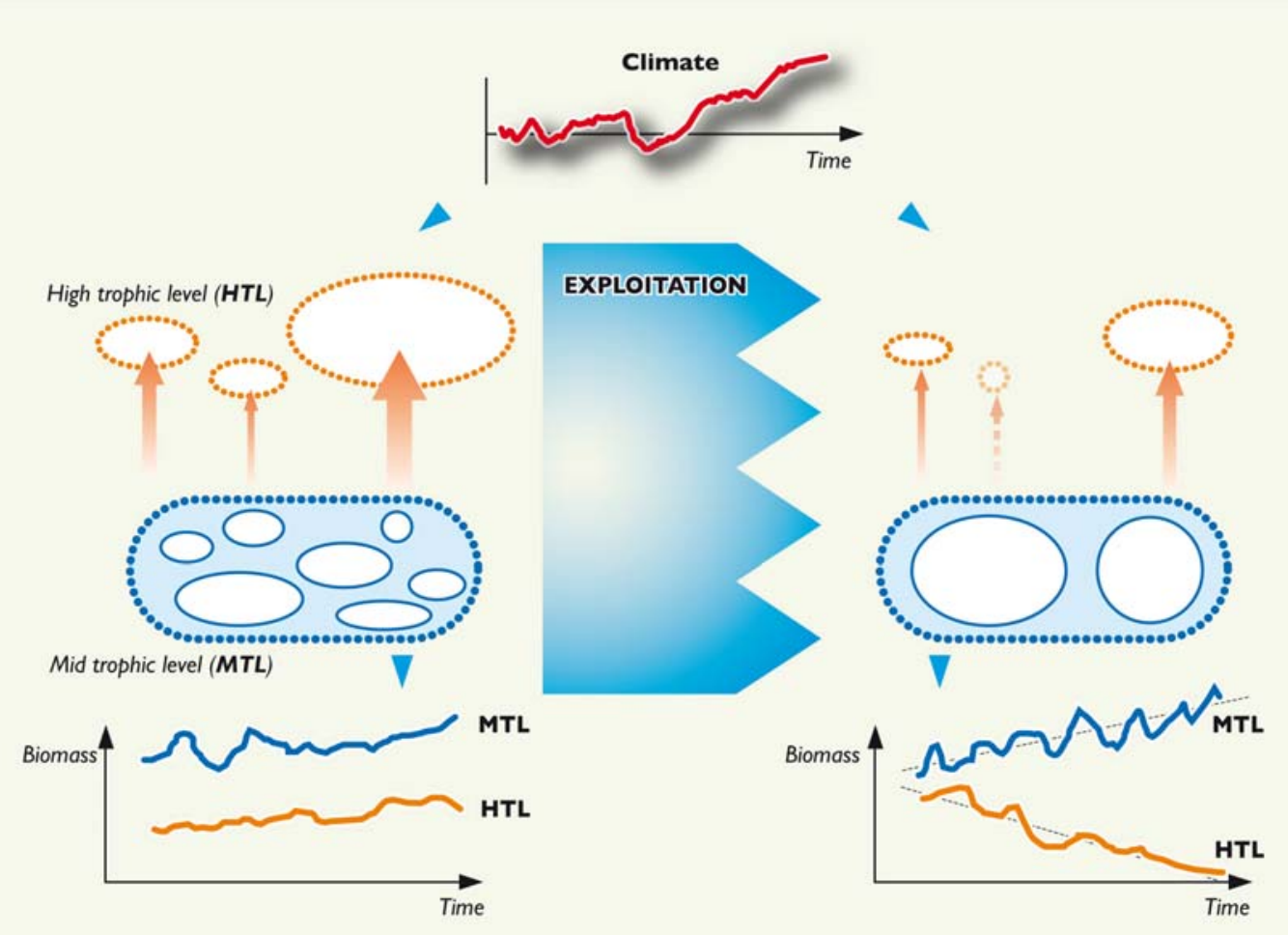

Figure 3. Schematic illustrating expected responses of unexploited and exploited simplified marine ecosystems to climate forcing. Left side shows an unexploited ecosystem with multiple high trophic level species which have large abundances (top left) supported by several mid-trophic level species with large and small abundances (middle left), and how their aggregate biomasses vary through time (bottom left). The right side illustrates how that same climate forcing is experienced by an ecosystem which has been exploited. The number and abundances of the high trophic level species have decreased (top right), and the mid-trophic level has been simplified to a smaller number of species but with larger abundances (middle right). The aggregate biomass of these mid-trophic levels now tracks the climate forcing more closely, whereas the high trophic levels decline in abundance due to exploitation (bottom right). 